University for Business and Technology in Kosovo

UBT Knowledge Center

Oct 28th, 2:00 PM - 3:30 PM

\title{
Beam- Column joints for R/C Structures According to EN 1998-1:2004
}

Xhemshir Mulliqi

University of Zagreb, xhemshir_mulliqi@yahoo.com

Follow this and additional works at: https://knowledgecenter.ubt-uni.net/conference

Part of the Civil Engineering Commons

\section{Recommended Citation}

Mulliqi, Xhemshir, "Beam- Column joints for R/C Structures According to EN 1998-1:2004" (2017). UBT International Conference. 47.

https://knowledgecenter.ubt-uni.net/conference/2017/all-events/47

This Event is brought to you for free and open access by the Publication and Journals at UBT Knowledge Center. It has been accepted for inclusion in UBT International Conference by an authorized administrator of UBT Knowledge Center. For more information, please contact knowledge.center@ubt-uni.net. 


\title{
Beam- Column joints for R/C Structures According to EN 1998-1:2004
}

\author{
Xhemshir Mulliqi ${ }^{1}$ \\ ${ }^{1}$ Doctoral student University of Zagreb, Faculty of Civil Engineering \\ xhemshir_mulliqi@yahoo.com
}

\begin{abstract}
Joints are crucial zones for the transfer internal forces effectively between the connecting elements like beams and columns. The behaviour of reinforced concrete moment resisting frame structures in recent earthquakes all over the world has highlighted the consequences of poor performance of beam column joints. The basic requirement of design is that the joint must be stronger than the adjoining hinging members, usually the beams or columns. This paper aims to present design approach for Beam- Column joints for reinforced concrete (R/C) structures according to the EN 1998-1:2004.
\end{abstract}

Keywords:Beam-Column joints,reinforced concrete frames, strong column /weak beam,shear strength , diagonal cracking

\section{Introduction}

Beam-column joints are the most crucial parts of seismic-resistant $\mathrm{R} / \mathrm{C}$ frames because in their limited volume the stress state field that develops due to seismic action is very high.[3]Joints are crucial zones for the transfer internal forces effectively between the connecting elements like beams and columns. In normal design practice for gravity loads, the design check for joints is not usually critical in reinforced concrete (RC) frames and hence not warranted in general.The behaviour of reinforced concrete moment resisting frame structures in recent earthquakes all over the world has highlighted the consequences of poor performance of beam column joints. The basic requirement of design is that the joint must be stronger than the adjoining hinging members, usually the beams or columns. Early works of Paulay et al. (Pauley et al. 1978) established traditional truss and strut modeltoexplain the shear resistance mechanism without making distinction of interior and exterior beam-column joints. But they gave no explanation to the reason why the strength of exterior joint islower than that of interior joint based on the model. This paper aims to present design approach for Beam- Column joints for reinforced concrete (R/C) structures according to the EN 1998-1:2004.[1]

\section{Beam-column joints}

Beam column joints are generally classified with respect to geometrical configuration and identified as interior, exterior and corner joints as shown in (Fig. 1).

- The design of joints to shear developed by Park and Paulay (1975) and Paulay and Priestley (1992).

- The design method adopted by EC 8-1/2004. 
- The design of joints to shear developed by Tsonos (Tsonos et al., 1995; Tsonos, 1999, 2001).

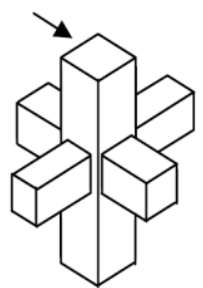

a)Interior joint

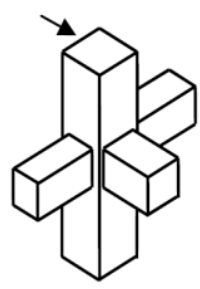

b) Exterior joint

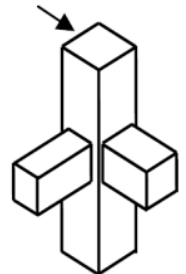

c)Cornerjoint

Fig. 1. Types of joints in a moment resisting frame

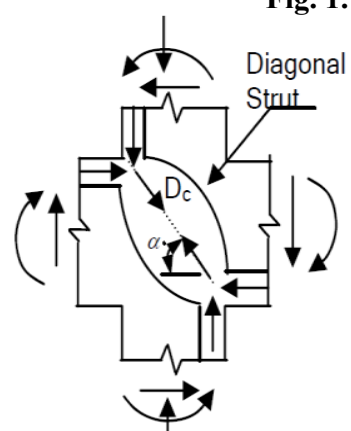

a)Strut mechanism

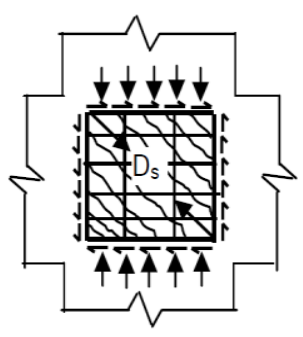

b)Truss mechanism

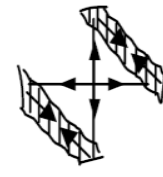

c)Componets of truss

Fig. 2. Types of joints in a moment resisting frame

The principal mechanisms of failure of a beam-column joint are:

- shear failure within the joint

- Anchorage failure of bars, if anchored within the joint

- Bond failure of beam or column bars passing through the joint

The failure modes of some basic types of joints are depicted in (Fig.3 and Fig.4)

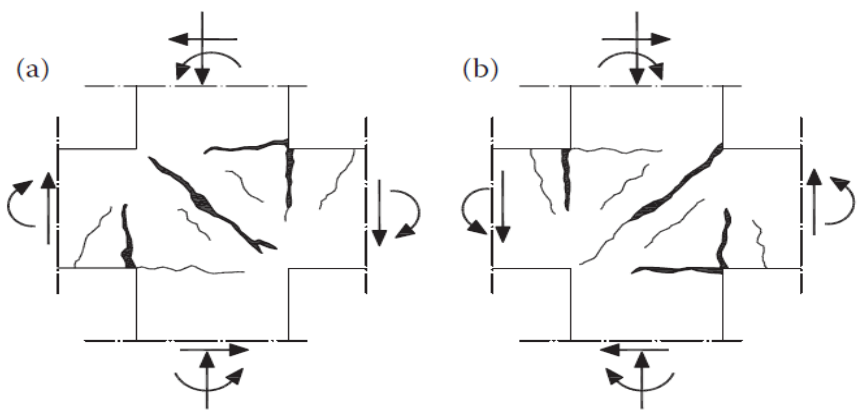

(c)

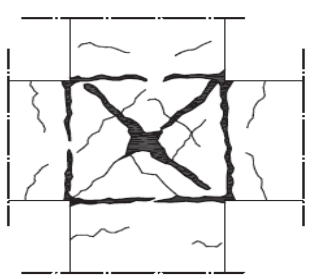

Fig.3. Failure of interior joint: (a) seismic action in the right to left direction; (b) seismic action in the left to right direction; (c) cyclic seismic action. 

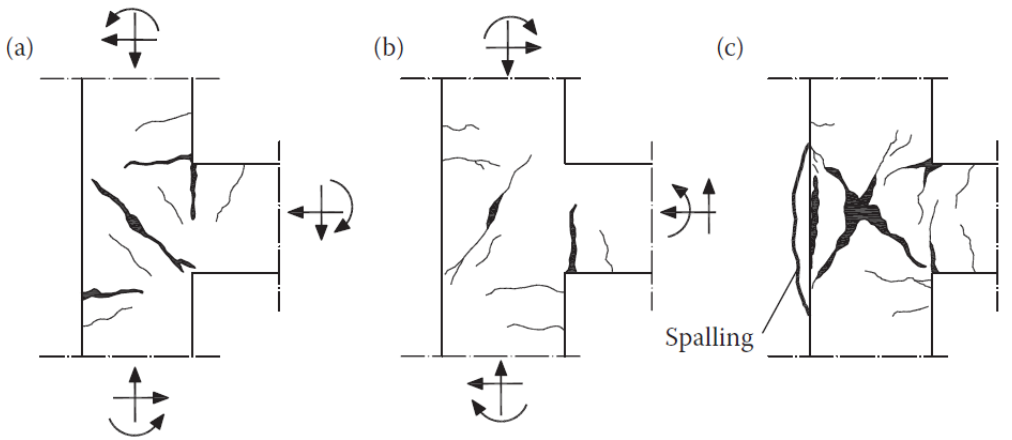

Fig. 4.Failure of exterior joint in a multi-storey building: (a) moments inducing compression at the lower fibre of the beam; (b) moments inducing compression at the upper fibre of the beam; (c) cyclic bending moment loading.

\section{Horizontal shear acting in Beam-column joints}

The horizontal shear acting on the core of a joint between primary seismic beams and columns shall be determined taking into account the most adverse conditions under seismic actions, i.e. capacity design conditions for the beams framing into the joint and the lowest compatible values of shear forces in the other framing elements.

Simplified expressions for the horizontal shear force acting on the concrete core of the joints may be used as follows:

a) for interior beam-column joints:

$$
V_{\mathrm{jhd}}=\gamma_{R d}\left(A_{s 1}+A_{s 2}\right) f_{y d}-V_{\mathrm{c}}
$$

b) for exterior beam-column joints:

$$
V_{\mathrm{jhd}}=\gamma_{R d}\left(A_{s 1}\right) f_{y d}-V_{\mathrm{c}}
$$

where

$A_{s 1}$ is the area of the beam top reinforcement;

$A_{s 2}$ is the area of the beam bottom reinforcement;

$V_{\mathrm{c}}$ is the shear force in the column above the joint, from the analysis in the seismic design situation;

$\gamma_{R d}$ is a factor to account for overstrength due to steel strain-hardening and should be not less than 1,2 .

\section{Nominal Shear Stress of the joint}

EN 1998-1:2004 also has limited the nominal shear stress, jhv within interior beam column joint to be less than the stress value given by the expression: 
a)At interior beam-column joints the following expression should be satisfied:

$$
V_{\mathrm{jhd}} \leq \eta f_{c d} \sqrt{1-\frac{v_{d}}{\eta}} b_{j} h_{j c}
$$

where

$\eta=0,6\left(1-f_{c k} / 250\right)$; denotes the reduction factor on concrete compressive strength due to tensile strains in transverse direction.

$h_{j c}$ is the distance between extreme layers of column reinforcement;

$b_{j}$ is the width of the joint;

$v_{d}$ is the normalised axial force in the column above the joint;

and $f_{c k} i$ s given in $\mathrm{MPa}$.

b)At exterior beam-column joints $V_{\text {jhd }}$ should be less than $80 \%$ of the value given by the righthand-side of expression (3) where:

$V_{\text {jhd }}$ is given by expressions (1) and (2) respectively;

and the effective joint width $b_{j}$ is:

a) if $b_{c}>b_{w}: b_{j}=\min \left\{b_{c} ;\left(b_{w}+0.5 \cdot h_{c}\right)\right\}$;

b) if $b_{c}<b_{w}: b_{j}=\min \left\{b_{w} ;\left(b_{c}+0.5 \cdot h_{c}\right)\right\}$;

\section{Confinement of the joint}

\section{Horizontal reinforcement}

Shear reinforcement of the joint (horizontal reinforcement of hoops and vertical reinforcement of intermediate longitudinal bars) should satisfy the following expression:

$$
\frac{A_{s h} \cdot f_{y w d}}{b_{j} \cdot h_{j w}} \geq \frac{\left(\frac{V_{\text {jhd }}}{b_{j} \cdot h_{j c}}\right)^{2}}{f_{c t d}+v_{d} f_{c d}}-f_{c t d}
$$

Where

$A_{s h}$ is the total area of the horizontal hoops;

$V_{\text {jhd }}$ is as defined in expressions (1) and (2);

$h_{j w}$ is the distance between the top and the bottom reinforcement of the beam;

$h_{j c}$ is the distance between extreme layers of column reinforcement;

$b_{j}$ is as defined in expression (4)and (5);

$v_{d}$ is the normalised design axial force of the column above $\left(v_{d}=N_{E d} / A_{C} \cdot f_{c d}\right)$;

$f_{c t d}$ is the design value of the tensile strength of concrete, in accordance with EN 1992-1$1: 2004$. 
However, EN code also imposes a requirement to maintain the integrity of the joint after diagonal cracking and hence the necessary reinforcement to be provide for interior is given as:

a) In interior joints:

$$
A_{s h} f_{y w d} \geq \gamma_{R d}\left(A_{s 1}+A_{s 2}\right) f_{y d}\left(1-0.8 v_{d}\right)
$$

b) In exterior joints:

$$
A_{s h} f_{y w d} \geq \gamma_{R d} A_{s 2} f_{y d}\left(1-0.8 v_{d}\right)
$$

where $\gamma_{R d}$ is equal to $1,2(\mathrm{cf} 5.5 .2 .3(2))$ and the normalised axial force $v_{d}$ refers to the column above the joint in expression (7), or to the column below the joint in expression (8).

The horizontal hoops should be uniformly distributed within the depth $h_{j w}$ between the top and bottom bars of the beam. In exterior joints they should enclose the ends of beam bars bent toward the joint.

\subsection{Vertical shear reinforcement}

EN 1998-1:2004 requires only $2 / 3$ of the horizontal shear reinforcement as vertical reinforcement

$$
A_{s v, i} \geq(2 / 3) \cdot A_{s h} \cdot\left(h_{j c} / h_{j w}\right)
$$

- The horizontal confinement reinforcement in joints of primary seismic beams with columns should be not less than that specified in 5.4.3.2.2(8)-(11) for the critical regions of columns.[1]

- If beams frame into all four sides of the joint and their width is at least threequarters of the parallel cross-sectional dimension of the column, the spacing of the horizontal confinement reinforcement in the joint may be increased to twice, but may not exceed $150 \mathrm{~mm}$.

- At least one intermediate (between column corner bars) vertical bar shall be provided at each side of a joint of primary seismic beams and columns.

\section{Anchorage of beam reinforcement in joints}

The diameter of beam longitudinal reinforcement $d_{b l}$ passing through beam column joints must be in accordance with the following limitations.

a)for interior beam-column joints: 


$$
\frac{d_{b l}}{h_{c}} \leq \frac{7.5 \cdot f_{c t m}}{\gamma_{R d} \cdot f_{y d}} \cdot \frac{1+0.8 v_{d}}{1+0.75 \kappa_{D} \cdot \rho_{2} / \rho_{1 \max }}
$$

a) for exterior beam-column joints:

where

$$
\frac{d_{b l}}{h_{c}} \leq \frac{7.5 \cdot f_{c t m}}{\gamma_{R d} \cdot f_{y d}} \cdot\left(1+0.8 v_{d}\right)
$$

$h_{c}$ is the width of the column parallel to the beam

$f_{c t m}$ is the mean value of the tensile strength of concrete

$f_{y d}$ is the design value of the yield strength of steel

$v_{d}$ is the normalised minimum design axial force in the column for the seismic design combination $\left(v_{d}=N_{E d} / A_{C} \cdot f_{c d}\right)$

$\kappa_{D}$ is the factor reflecting the ductility class $\kappa_{D}=1.0$ for DCH buildings $\kappa_{D}=0.66$ for DCM buildings

$\rho_{1 \text { max }}$ is the maximum allowed tension steel ratio in critical regions $\rho_{2}$ is the compression steel ratio

\begin{tabular}{|c|c|c|c|c|c|c|c|c|c|c|}
\hline Concrete & $\mathrm{C} 16$ & $\mathrm{C20}$ & $\mathrm{C} 25$ & $\mathbf{C 3 0}$ & C35 & 40 & $\mathrm{C45}$ & $\mathrm{C50}$ & $\mathrm{C55}$ & $\mathrm{C60}$ \\
\hline \multicolumn{11}{|c|}{$d_{b l}, \max (\mathrm{mm}) \mathbf{D C M}$} \\
\hline$\kappa_{D}=2 / 3+$ & 17 & 20 & 24 & 26 & 29 & 32 & 35 & 37 & 38 & 40 \\
\hline $\begin{array}{l}\gamma_{\mathrm{Rd}}=1.0 \\
d_{b l}, \max (\mathrm{mm}\end{array}$ & 22 & 25 & 30 & 33 & 36 & 40 & 43 & 47 & 48 & 50 \\
\hline$\kappa_{D}=1.0+$ & 13 & 15 & 18 & 20 & 22 & 24 & 26 & 28 & 29 & 30 \\
\hline$\gamma_{\mathrm{Rd}}=1.2$ & 18 & 21 & 25 & 28 & 30 & 33 & 36 & 39 & 40 & 42 \\
\hline
\end{tabular}

Table 2.Maximum diameter sizes for a column width $\mathrm{hc}=500 \mathrm{~mm}[3]$

Steel Class B500c: $f_{y d}=500 / 1.15 \mathrm{MPa}, v_{d}=0,40, \rho^{\prime} / \rho \max =0.50$.

(a)

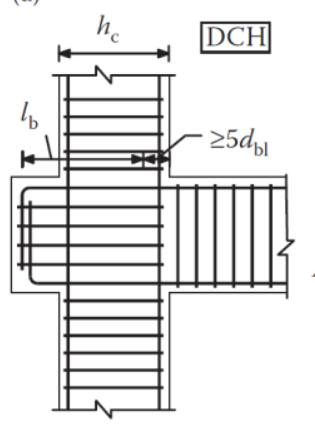

(b)

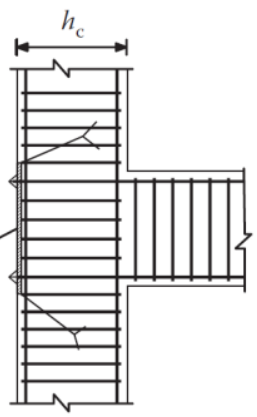

(c)

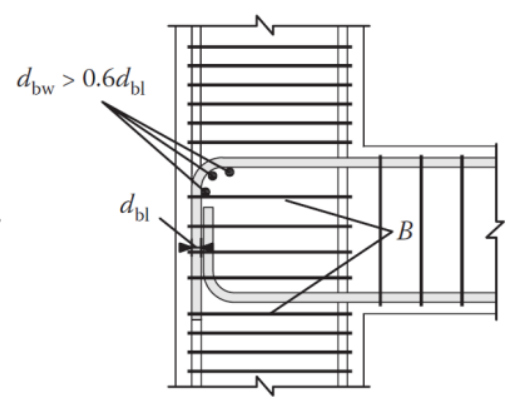

Key

A: anchor plate

$\mathrm{B}$ : hoops around column bars 
Fig. 5. Additional measures for anchorage in exterior beam-column joints: (a) beam extension; (b) anchorage plate; (c) bonds and transverse reinforcement. [1]

\section{Conclusions}

- The behaviour and expected performance of flexural members of reinforced concrete moment resisting frames can be realised only when the joints are strong enough to sustain the severe forces set up under lateral loads.

- The effect of higher concrete grade in reducing the column depth has been included in EN 1998-1:2004.

- From the table1. it may be concluded that the ratio $h_{c} / d_{b l}$, for internal joints, ranges from 38.4 (C16) to 17.8 (C50) for DCH buildings.

- The requirements imposed by expressions (10) and (11) are crucial at the prestudy stage for the choice of the dimensions of the columns and the concrete class in relation to the diameters of the rebars that are going to be used in beams

- EN code require $60 \%$ of horizontal shear reinforcement as vertical shear reinforcement. EN code accept the intermediate column bars as a part of vertical shear reinforcement.

- The detailing requirements ensure adequate confinement of core concrete and preclude the buckling of longitudinal bar. The horizontal and vertical transverse reinforcements are to be distributed within the joint to resist the diagonal shear cracking and to contain the transverse tensile strain in core concrete.

\section{References}

1. .EC8-1/EN 1998-1. 2004. Design of Structures for Earthquake Resistance: General Rules, Seismic Actions and Rules for Buildings. CEN, Brussels, Belgium.

2. .EC2-1-1/EN 1992-1-1. 2004. Design of Concrete Structures-Part 1-1: General Rules and Rules for Buildings. BSI, CEN, Brussels, Belgium.

3. .George G. Penelis and Gregory G. Penelis,"Concrete Buildings in Seismic Regions”,2014

4. Uma, S. R., "Seismic Behaviour of Beam Column Joints in Moment Resisting Reinforced Concrete Frame Structures," submitted to Indian Concrete Journal, October 2004

5. Paulay, T., Park, R. and Priestley, M. J. N. (1978), "Reinforced Concrete Beam-Column Joints under Seismic Actions," Journal of ACI, 75(11), 585-593

6. . Park, R. and Paulay, T. 1975. Reinforced Concrete Structures. J. Wiley \& Sons, New York.

7. .Paulay, T. and Priestley, M.J.N. 1992. Seismic Design of Reinforced Concrete and Masonry Buildings. J. Wiley \& Sons, New York. 